\title{
Tobacco Industry Fingerprints on Delaying Implementation of Pictorial Health Warnings in the Western Pacific
}

\author{
Yen Lian Tan ${ }^{1 *}$, Judith Mackay ${ }^{2}$, Mary Assunta Kolandai ${ }^{1}$, E Ulysses Dorotheo ${ }^{1}$
}

\begin{abstract}
Objective: This case series describes tobacco industry tactics and strategies used to interfere, derail, delay, and weaken the development of effective health warning regulations in Malaysia, Cambodia, the Philippines, and Hong Kong. Methods: A historical review of official reports, news articles, and gray literature was undertaken to identify tobacco industry tactics and strategies to hamper government efforts in implementing stronger pictorial health warning regulations in four Asian jurisdictions (Cambodia, Hong Kong, Malaysia, and the Philippines). Results: Nineteen countries/jurisdictions in the WHO Western Pacific region currently require pictorial health warnings on cigarette packs, including some of the world's largest, in line with the WHO Framework Convention on Tobacco Control Article 11 Guidelines. In the four jurisdictions examined, tobacco industry interference consisted of lobbying and misinformation of high-level government officers and policy-makers, distributing industry-friendly legislative drafts, taking government to court, challenging government timelines for law implementation, and mobilizing third parties. Strong political leadership and strategic advocacy enabled governments to successfully overcome this industry interference. Conclusion: The tobacco industry uses similar tactics in different jurisdictions to derail, delay, and weaken the implementation of effective health warning policies. Identifying and learning from international experiences can help anticipate and defeat such challenges.
\end{abstract}

Keywords: Tobacco industry- pictorial health warnings- interference- WHO FCTC-Asia

Asian Pac J Cancer Prev, 21, Progress of Tobacco Control in the Western Pacific Region Suppl, 23-25

\section{Introduction}

Effective health warnings on all tobacco product packs are mandated under Article 11 of the WHO Framework Convention on Tobacco Control (FCTC). To this end, the Article 11 Guidelines, adopted at the third Conference of Parties in 2008, recommend 50\% or more but not less than $30 \%$, prominent pictorial health warnings (PHWs). Among 118 countries/jurisdictions worldwide that apply PHWs, 19 are in the Western Pacific Region (Canadian Cancer Society, 2018). The tobacco industry has routinely interfered to derail, delay, and weaken effective health warning regulations. Industry tactics in Malaysia, Cambodia, the Philippines and Hong Kong were strikingly similar, despite the diverse forms of government in these Asian jurisdictions.

\section{Materials and Methods}

Official government reports, news articles, and gray literature relevant to PHW policy development in the four focus jurisdictions were identified and analyzed to identify tobacco industry tactics and strategies to hamper government efforts in implementing stronger PHW regulations in four Asian jurisdictions (Cambodia, Hong Kong, Malaysia, and the Philippines).

\section{Results}

\section{The Case of Malaysia}

The Ministry of Health $(\mathrm{MOH})$ Malaysia started advocating for PHWs in 2002 when drafting amendments to the Control of Tobacco Product Regulations (CTPR). Tobacco companies objected to the inclusion of PHWs, claiming that PHWs violate their intellectual property rights and would damage their brands' image. The Malaysian $\mathrm{MOH}$ subsequently omitted the $\mathrm{PHW}$ provision in the amendment (CTPR 2004) to avoid deferment of the regulation's passage as a prerequisite for FCTC ratification.

In December 2005, Malaysia officially became a Party to the WHO FCTC, committing to implement strong tobacco control policies; however, between 2004 and 2008, the tobacco industry continued to undermine government efforts by proposing $30 \%$ text-only warnings on tobacco product packaging, instead of PHWs, to fulfill the bare minimum requirement of the FCTC. The industry misled policy-makers with claims that substantial investments 
are required to print $\mathrm{PHW}$ - such as redesigning packaging, ordering printer drums from overseas (that take several months to arrive), and communicating changes to customers - using these excuses to request a longer implementation deadline. Despite these challenges, the Malaysian government introduced six rotating PHWs to be printed on the upper $40 \%$ of front and upper $60 \%$ of back panels of all cigarette packs, effective 1 January 2009, legislated under the CTPR as amended in September 2008 (Ministry of Health Malaysia, 2008). These policy changes are attributed to the government's strong political will to meet its FCTC obligations, as well as the influence of neighboring Singapore and Thailand, which had implemented PHWs in 2004 and 2005, respectively.

After the implementation of PHWs in 2009, the tobacco industry introduced various alternative pack shapes and designs in an attempt to dilute the effectiveness of the PHWs (Tan and Foong, 2012) and alternative descriptors for quality variations to undermine the ban on misleading descriptors (Tan and Foong, 2014). In response, the CTPR (Amendment) 2013 further expanded the descriptor ban to include any term that states the grading, quality or supremacy of, or is fanciful and not relevant to, the physical characteristics of the tobacco products.

\section{The Case of Cambodia}

In 2015, after passage of the national tobacco control law stipulating at least 50\% PHW in the Khmer language on all cigarette packs, the tobacco industry tried to undermine the draft $\mathrm{MOH}$ sub-decree to implement PHWs by submitting letters of concern to high-level officials and other ministries. Tobacco companies also mobilized third parties - their distributors - to support their lobbying efforts. Huotraco, the distributor of foreign cigarette brands in Cambodia, reportedly submitted a letter to the then Deputy Prime Minister, opposing a PHW size of more than $50 \%$ and requesting 12 months or longer lead time to comply. The newly formed Association of the Tobacco Industry of Cambodia was also reported to have submitted a similar letter denying the effectiveness of large PHWs and claiming PHWs would increase the consumption of illegal tobacco products and reduce government revenues. The Asia Pacific Travel Retail Association and Dufry (Cambodia) Ltd (a global travel retailers chain) was reported to have submitted letters to the President of the National Assembly requesting that tobacco products sold at duty-free outlets be exempted from the PHW requirement; they claimed incorrectly that tobacco products sold at duty-free outlets should follow international standards and carry small English-language warnings rather than local health warnings.

With strong $\mathrm{MOH}$ commitment, as well as constant technical support from and close communications with local tobacco control advocates to counter tobacco industry interference, the PHW sub-decree was legislated on 22 October 2015 (Royal Government of Cambodia, 2015). The tobacco industry was given nine months (i.e. by 23 July 2016) to apply 55\% PHWs on all cigarette packs (Ministry of Health Cambodia, 2016).

Prior to this, in 2009, the tobacco industry had successfully defeated PHWs being implemented when a draft sub-decree on health warnings, which included five rotating PHWs, was watered down to a mandatory bottom-30\% text-only warning after the industry lobbied government agencies and politicians, claiming that PHWs violated their intellectual property rights and Cambodia's international trade treaty obligations (Tan, 2010).

\section{The Case of the Philippines}

In 2007-2008, pro-health legislators filed bills to have PHWs cover $60 \%$ of the principal display areas of packs, but pro-industry legislators, after allegedly receiving bribes, firmly blocked the bill from being discussed beyond the health committee, claiming that PHWs would kill the industry (Rufo, 2009).

Because of Congress's failure to pass the bill, the Philippine Department of Health $(\mathrm{DOH})$ issued Administrative Order (AO) No. 2010-0013 in 2010, requiring nine rotating PHWs to cover $30 \%$ of the upperfront and $60 \%$ of the upper-back of the pack in addition to the existing 30\% text warning on the front (Department of Health Philippines, 2010).

Claiming that DOH was usurping legislative power, the Philippine Tobacco Institute argued that the AO violated Republic Act (RA) 9211, which prohibited the printing of warnings other than the existing text warnings, and that tobacco companies would face hefty fines and imprisonment for complying with the AO (Andreo, 2010). Subsequently, five tobacco companies filed separate court cases in the regional trial courts questioning the AO's validity (WHO, 2011). Unfortunately, the Marikina Trial Court granted Fortune Tobacco Corporation's petition for a preliminary injunction, effectively barring the $\mathrm{DOH}$ from implementing the AO (Mark, 2010).

In 2012, the Philippines passed a landmark Sin Tax Reform Act (RA 10351) that raised tobacco taxes to discourage smoking and provide sustainable revenues for universal health coverage. In 2013, buoyed by the successful tobacco tax reform, pro-health legislators pushed for PHWs on the upper $85 \%$ of the front and back of packs and a ban on misleading descriptors, prompting the industry to respond with its own PHW bill, proposing a $30 \%$ PHW on the back in addition to the existing $30 \%$ text-only warning on the front, as well as an alternate bill simply adding a $30 \%$ text warning to the lower back in minimum compliance with the FCTC.

After months of deliberations and compromises, the Graphic Health Warnings Law (RA 10643) was finally signed into law in July 2014. The law requires 12 rotating, $50 \%$ PHWs to be replaced every 24 months, additional text information on $30 \%$ of one side panel, and a ban on misleading descriptors. Aside from the smaller PHW size, other concessions to the industry included: requiring PHWs to be in the lower rather than upper portion of principal pack surfaces, and giving the industry 20 months from publication of the PHW templates for full compliance. Seemingly unsatisfied with these concessions, the industry tried unsuccessfully to weaken the implementing rules and regulations (IRR), by arguing for a narrow interpretation of the law and exclusion of products sold in duty-free stores. Due to the many instances of tobacco industry interference, the IRR took more than a year to be finalized 
and officially published in February 2016 (Department of Health Philippines, 2016).

\section{The Case of Hong Kong}

In 2015, the Hong Kong government took steps to enhance the existing 2007 PHW requirements by proposing larger $(85 \%) \mathrm{PHWs}$, increasing the number of rotating PHWs from six to 12, and adding the Hong Kong Quitline number on the pack. Similar to arguments used in Cambodia, the tobacco industry claimed that larger PHWs would lead to cigarette smuggling. Industry allies - the Coalition of Hong Kong Newspaper and Magazine Merchants and the wholesale and retail sectors, including elected legislators - shared concerns that it would affect their business. Tobacco vendors threatened to protest if $85 \%$ warnings were adopted $(\mathrm{Ng}, 2017)$.

The amendment proposal was scrutinized by the Legislative Council, where other members outvoted the few pro-tobacco industry legislators who had expended great efforts to obstruct the bill. After more than a year's delay, the Smoking (Public Health) (Notices) (Amendment) Order 2017 was gazette (Hong Kong Legislative Council, 2017), requiring health messages to be printed in Chinese on one side and in English on the other, with one year (by 20 June 2018) for full compliance by the tobacco industry. The government was able to resist the industry by a combination of use of international and national data, global experience, WHO FCTC recommendations, media campaigns, mobilizing international support, consulting the legal departments within the government, and by showing laudable determination to stand up to the industry.

In conclusion, globally, tobacco companies routinely use a range of tactics to undermine effective legislation and other measures to reduce tobacco use, including blocking implementation of prominent PHWs on tobacco packs. These tactics to oppose strong health warning measures include lobbying and submitting letters with misinformation to high-ranking government officers and policy-makers, distributing industry-friendly legislative drafts, bribery, taking government to court, challenging government timelines for law implementation, and mobilizing third parties. These have a measurable delaying effect on governments introducing such measures and can cause a regulatory chilling effect on other countries contemplating the same actions. These four Asian governments have demonstrated that these challenges are surmountable with strong political leadership and strategic advocacy.

\section{Statement conflict of Interest}

The authors declare they have no conflict of interest.

\section{References}

Andreo C (2010). Tobacco firms call for stop to picture health warnings, GMA News Online, 2010 June 3. Available from: http://www.gmanetwork.com/news/news/nation/192570/ tobacco-firms-call-for-stop-to-picture-health-warnings/ story/ [Accessed 20 September 2017].

Canadian Cancer Society (2018). Cigarette Package Health
Warnings: International Status Report, Sixth Edition, September 2018. Available from: https://www.fctc.org/ wp-content/uploads/2018/10/CCS-international-warningsreport-2018-English-2-MB.pdf.

Department of Health Philippines (2010). Administrative Order No. 2010 - 0013, 2010 May 12.

Department of Health Philippines (2016). Implementing Rules and Regulations of Republic Act No. 10643 "An Act to Effectively Instill Health Consciousness through Graphic Health Warnings on Tobacco Products" Otherwise known as "The Graphic Health Warnings Law". Manila, 9 February, 2016.

Hong Kong Legislative Council (2017). Interpretation and General Clauses Ordinance: Resolution of the Legislative Council - Smoking (Public Health) (Notices) (Amendment) Order 2017, 2017 June 14. Available from: https://www. elegislation.gov.hk/hk/2017/ln126!en.

Mark DM (2010). Court stops graphic health warnings on cigarette packs, GMA News Online, 2010 July 7. Available from: http://www.gmanetwork.com/news/news/ nation/195427/court-stops-graphic-health-warnings-oncigarette-packs/story/ [Accessed 20 September 2017].

Ministry of Health Cambodia (2016). Prakas on Legal procedure for printing of Health Warning in Khmer Language and Pictorial on Tobacco Products Packages. Phnom Penh, 2016 February 15.

Ministry of Health Malaysia (2008). Food Act 1983, Control of Tobacco Product (Amendment) Regulations. Kuala Lumpur: Percetakan Nasional Malaysia Berhad (PNMB), 2008.

$\mathrm{Ng} \mathrm{K-C} \mathrm{(2017).} \mathrm{Hong} \mathrm{Kong} \mathrm{vendors} \mathrm{warn} \mathrm{of} \mathrm{protests} \mathrm{if} \mathrm{larger}$ warnings are printed on cigarette packs, South China Morning Post, 2017 April 24. Available from: http:// www.scmp.com/news/hong-kong/health-environment/ article/2090134/hong-kong-vendors-warn-protests-if-largerwarnings.

Royal Government of Cambodia (2015). Sub-Decree on Printing of Health Warning in Khmer Language and Pictorial on Tobacco Products Packages. Phnom Penh, 2015 October 22.

Rufo A (2009). Congressmen gang up on anti-smoking graphic warning bill, Newsbreak, 2009 January 17. Available from: http://archives.newsbreak-knowledge.ph/2009/01/17/ congressmen-gang-up-on-anti-smoking-graphic-warningbill/.

Tan YL (2010). It's only words: Interference in implementing health warnings in Cambodia. Bangkok: Southeast Asia Tobacco Control Alliance (SEATCA); 2010 August. Available from: https://seatca.org/dmdocuments/its $\% 20$ only $\% 20$ words $\% 20$ optimized $1 . p d f$.

Tan YL, Foong K (2012). How the Malaysian tobacco industry exploits loopholes in pictorial health warnings. Tob Control, 21, 55-6.

Tan YL, Foong K (2014). Tobacco industry tangos with descriptor ban in Malaysia. Tob, Control, 23, 84-7.

World Health Organization (2011). Joint national capacity assessment on the implementation of effective tobacco control policies in the Philippines. Geneva: World Health Organization. Available from: https://apps.who.int/iris/ handle/10665/44764.

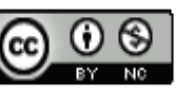

This work is licensed under a Creative Commons AttributionNon Commercial 4.0 International License.

Asian Pacific Journal of Cancer Prevention, Vol 21 